\title{
Is low-level laser therapy (LLLT) effective in relieving the symptoms of temporomandibular disorders (TMDs)? A systematic review
}

\author{
¿La terapia láser de bajo nivel (LLLT) es eficaz para aliviar los síntomas \\ de los trastornos temporomandibulares (TTM)? Revisión sistemática
}

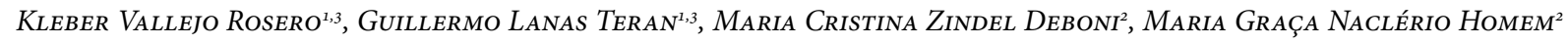

DDS, Doctoral student, Department of Oral Surgery, Dental School, University of S o Paulo, S o Paulo, SP, Brazil

DDS, PhD, Associate Professor, Department of Oral Surgery, Dental School, University of S o Paulo, S o Paulo, SP, Brazil

Associate Professor, Department of Oral Surgery, Dental School, Universidad Central de Ecuador, Quito, Ecuador

\begin{abstract}
Introduction: LLLT is used in various clinical situations for the relief of postoperative inflammatory symptoms in TMD cases. Many treatment protocols use laser radiation, but there is still no evidence as to whether one of them is superior to all the other. The objective was to establish whether there is evidence that LLLT can reduce the main symptoms of TMDs and to determine the most effective application protocol. Methods: a systematic review of the literature was performed in the main databases: PubMed, Scopus and

Keywords: temporomandibular disorders, orofacial pain, low-level laser therapy, systematic review

Web of Science, by independent researchers who evaluated studies using different LLLT protocols to treat TMD symptoms, considering specific outcomes such as pain, mouth opening and jaw movements. Results: thirteen studies fully met the eligibility criteria. The most used laser type was GaAlAg, with a wavelength of $830 \mathrm{~nm}$, number of applications ranging from 8 to 10, and 4 weeks of follow-up. Conclusions: LLLT may be considered as an alternative for the relief of TMD symptoms; however, scientific evidence of one of the protocols being superior to the others could not be found.
\end{abstract}

\section{RESUMEN}

Introducci $\boldsymbol{n}$ : la terapia I ser de bajo nivel (LLLT por sus iniciales en ingl s) se utiliza en diversas situaciones cl nicas para el alivio de los s ntomas inflamatorios posoperatorios en casos de trastornos temporomandibulares (TTM). Hay muchos protocolos de tratamiento que utilizan radiaci $\mathrm{n}$ I ser, pero todav a no hay evidencia de que alguno sea superior a los dem s. El objetivo de la presente revisi $\mathrm{n}$ sistem tica consisti en determinar si hay evidencia de que la LLLT pueda reducir los principales s ntomas de los TTM y determinar el protocolo de aplicaci n m s eficaz. $\boldsymbol{M}$ todos: se realiz una revisi $\mathrm{n}$ sistem tica de la literatura en las principales bases

\section{Palabras clave:} trastornos temporomandibulares, dolor orofacial, terapia I ser de bajo nivel, revisi $\mathrm{n}$ sistem tica de datos, PubMed, Scopus y Web of Science, por parte de investigadores independientes que evaluaron los estudios utilizando diferentes protocolos de LLLT para tratar los s ntomas de los TTM, considerando resultados espec ficos como dolor, apertura de la boca y movimientos de la mand bula. Resultados: trece estudios cumplieron plenamente los criterios de elegibilidad. El tipo de I ser m s utilizado fue GaAlAg, con una longitud de onda de $830 \mathrm{~nm}, \mathrm{n}$ mero de aplicaciones que oscilan entre 8 y 10 , y 4 semanas de seguimiento. Conclusiones: la LLLT puede considerarse una alternativa para el alivio de los s ntomas de los TTM; sin embargo, no se pudo encontrar evidencia cient fica de que un protocolo sea superior a los dem $\mathrm{s}$.

Submitted: June 12/2018 - Accepted: May 28/2019

How to quote this article: Vallejo-Rosero K, Lanas-Teran G, Zindel-Deboni MC, Nacl rio-Homem MG. Is low-level laser therapy (LLLT) effective in relieving the symptoms of temporomandibular disorders (TMDs)? A systematic review. Rev Fac Odontol Univ Antioq. 2019; 31(1-2): 136-146. DOI: http:// dx.doi.org/10.17533/udea.rfo.v31n1-2a12 


\section{INTRODUCTION}

Temporomandibular disorders (TMDs) present orofacial symptoms such as pain, masticatory dysfunction, difficulty in opening the mouth, limited jaw movements and chronic inflammation of the temporomandibular joint (TMJ). ${ }^{1}$ Pain is the main symptom affecting the functioning of the masticatory system and is therefore recognized as a major source of disability that affects quality of life. ${ }^{2}$

In terms of TMD symptom relief, the literature discusses various clinical procedures, such as the use of occlusal splints, physical therapy and low-level laser therapy (LLLT). It is important for these actions to be supported by clinical evidence regarding their scientific benefits and efficacy. ${ }^{3,4}$

LLLT is one of the most used therapies today to treat symptoms such as inflammation and pain in TMDs. However, LLLT is not effective in the treatment of the disorder per se., ${ }^{2,5}$ Due to their analgesic and antiinflammatory effects, various types of lasers, such as helium-neon ( $\mathrm{HeNe}$ ) and arsenidegallium-aluminum (GaAlAs), are used in the management of TMDs, with each being used at different wavelengths. ${ }^{1,6,7}$ The treatment is considered non-invasive, fast and safe. ${ }^{8}$

The literature describes favorable results in many clinical trials using LLLT for the treatment of signs and symptoms such as pain and trismus, but there is no specifically established protocol in terms of energy intensity, power, exposure time and number of applications. ${ }^{8-11}$

Below we present a systematic literature review to establish whether there is evidence that LLLT can reduce the main symptoms of TMDs and to determine the most effective application protocol.

\section{METHODS}

This systematic review was performed according to Preferred Reporting Items for Systematic Review and Meta Analyses (PRISMA). ${ }^{12}$ It was recorded in the International Prospective Register of Systematic Review PROSPERO (CRD42017076612).

\section{Focal issue}

The PICO issue was as follows: whether there is evidence of an efficient protocol for the use of LLLT for TMD symptom relief.

\section{Search strategy}

Two independent researchers (KVR and GLT) conducted a search in the principal data portals, PubMed, Scopus and Web of Science, considering specific outcomes of TMD symptoms such as pain, mouth opening and jaw movements, treated using different LLLT protocols, until September 30, 2017, and considering the following keywords: ((temporomandibular joint) OR tmj disorder)) OR tmj disfunction)) AND laser therapy) OR low level laser therapy)) OR photobiomodulation)) AND oral facial pain.

\section{Inclusion and exclusion criteria}

Only articles written in English and that met the following eligibility criteria were included: a) randomized clinical trials; b) studies specifying the type of laser used, including comparison groups with other laser types, other treatments, or placebo; and c) those presenting outcomes such as pain, mouth opening and jaw movements. Duplicate studies were removed using tools from EndNote version 2.5.0. Studies without a control group or an abstract, those evaluating diseases other than TMJ and animal studies were excluded. 


\section{Data extraction}

After reading the titles and abstracts, two independent reviewers (KVR and GLT) selected the articles to be included. Disagreements between reviewers were resolved by consensus after discussion and evaluation by a third investigator (MCZD).

Articles meeting the inclusion criteria were read in full for data extraction onto an individualized form that included the type and place of study; age and sex of participants; qualification of the control or comparison group; type, power and length of laser wave; number of sessions; evaluation and results of the outcomes, and follow-up period.

\section{Bias evaluation}

After data extraction, the studies were evaluated for biases using RevMan software 5.3 (Review Manager Computer program Copenhagen: The Nordic Cochrane Centre, The Cochrane Collaboration, 2014), taking the following aspects into account: form of randomization and allocation of participants into experimental and control groups; whether there was blinding of participants and/or examiners; and whether there were any conflicts of interest.

\section{RESULTS}

A total of 126 articles were initially retrieved. Eight duplicate studies were removed, along with 113 studies that did not meet the eligibility criteria. Figure 1 shows the flowchart for the search and exclusion of articles.

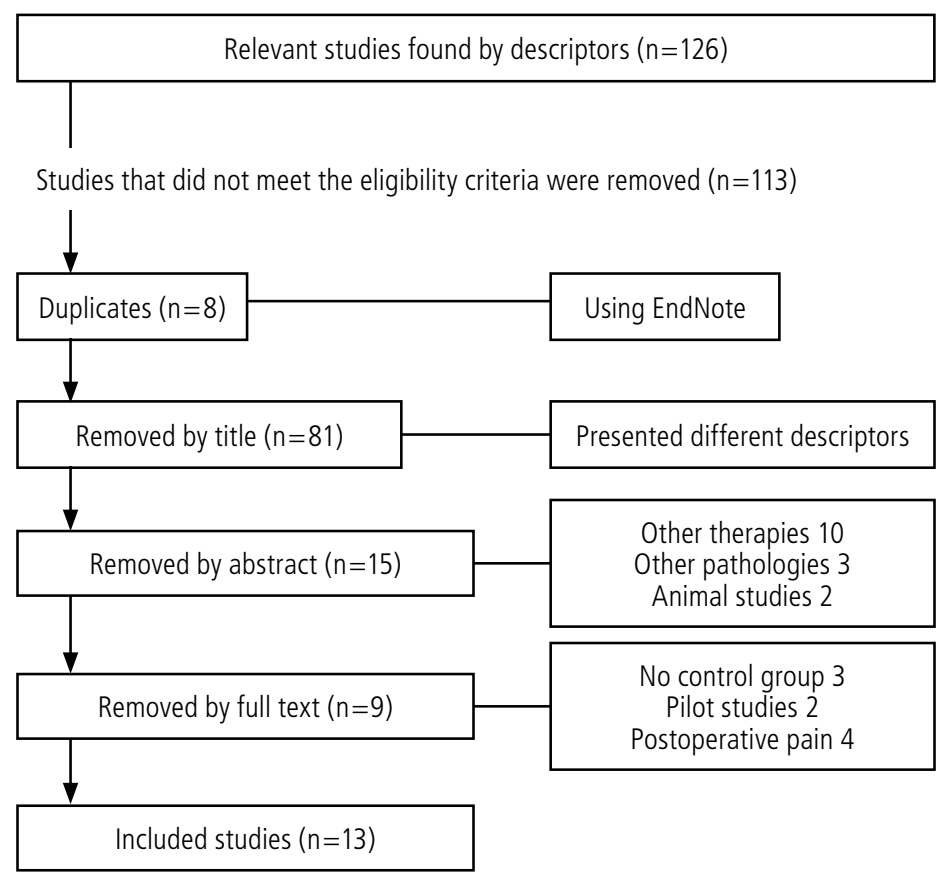

Figure 1. Flow diagram of the study selection stages

Source: by the authors 


\section{The characteristics of each selected study are shown in Table 1.}

Table 1. Summary of the characteristics of the selected clinical trials

\begin{tabular}{|c|c|c|c|c|c|c|c|c|c|c|}
\hline $\begin{array}{l}\frac{1}{3} \\
\frac{2}{2} \\
\frac{0}{3}\end{array}$ & 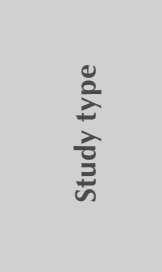 & 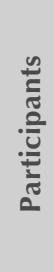 & $\begin{array}{l}\overline{0} \\
\overline{0} \\
0 \\
\dot{J} \\
\bar{d} \\
\text { Jે }\end{array}$ & 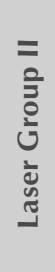 & $\begin{array}{l}\frac{0}{\bar{z}} \\
\frac{0}{0} \\
\frac{0}{0} \\
\frac{0}{0}\end{array}$ & 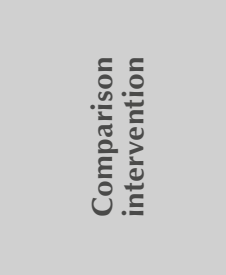 & 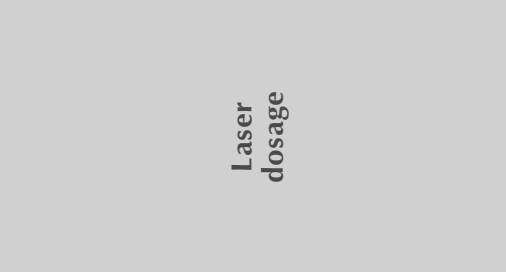 & 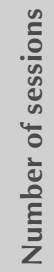 & $\frac{\overline{0}}{0}$ & 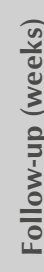 \\
\hline Conti, $1997^{9}$ & $\begin{array}{l}\text { Rand., pros., } \\
\text { double blind }\end{array}$ & 20 & 10 & & 10 & NA & GaAlAs - $830 \mathrm{~nm}, 100 \mathrm{~mW}, 4 \mathrm{~J} / \mathrm{cm}^{2}, 40 \mathrm{~s}$ & 3 & A, disconnected & 3 \\
\hline $\begin{array}{c}\text { Da Cunha et al, } \\
2008^{16}\end{array}$ & $\begin{array}{l}\text { Rand., pros., } \\
\text { double blind }\end{array}$ & 40 & 20 & & 20 & NA & GaAlAs $-830 \mathrm{~nm}, 500 \mathrm{~mW}, 4 \mathrm{~J} / \mathrm{cm}^{2}, 20 \mathrm{~s}$ & 4 & A, disconnected & 4 \\
\hline $\begin{array}{c}\text { Demirkol et al, } \\
2015^{17}\end{array}$ & $\begin{array}{l}\text { Rand., pros., } \\
\text { double blind, } \\
\text { parall. }\end{array}$ & 30 & 10 & 10 & 10 & Occlusal splints & $\mathrm{Nd}: Y a n g-1064 \mathrm{~nm}, 250 \mathrm{~mW}, 8 \mathrm{~J} / \mathrm{cm}^{2}, 20 \mathrm{~s}$ & 10 & NA & 3 \\
\hline $\begin{array}{l}\text { Emshoff et al, } \\
2008^{5}\end{array}$ & $\begin{array}{l}\text { Rand., pros., } \\
\text { double blind }\end{array}$ & 52 & 26 & & 26 & NA & HeNe $-632.8 \mathrm{~nm}, 30 \mathrm{~mW}, 1.5 \mathrm{~J} / \mathrm{cm}^{2}$ & 20 & A, disconnected & 8 \\
\hline $\begin{array}{l}\text { Fikácková et al, } \\
2007^{7}\end{array}$ & $\begin{array}{c}\text { Rand., pros., } \\
\text { double blind, } \\
\text { parall. }\end{array}$ & 80 & 33 & 28 & 19 & $\begin{array}{l}\text { GaAlAs - } 830 \mathrm{~mm} \\
400 \mathrm{~mW}, 15 \mathrm{~J} / \mathrm{cm}^{2}\end{array}$ & GaAlAs - $830 \mathrm{~mm}, 400 \mathrm{~mW}, 10 \mathrm{~J} / \mathrm{cm}^{2}$ & 10 & A, disconnected & 4 \\
\hline $\begin{array}{c}\text { Mazzetto et al, } \\
2010^{6}\end{array}$ & $\begin{array}{l}\text { Rand., pros., } \\
\text { double blind }\end{array}$ & 40 & 20 & & 20 & NA & GaAlAs $-830 \mathrm{~nm}, 40 \mathrm{~mW}, 5 \mathrm{~J} / \mathrm{cm}^{2}, 50 \mathrm{~s}$ & 8 & A, disconnected & 4 \\
\hline Öz et al, $2010^{14}$ & $\begin{array}{l}\text { Rand., pros., } \\
\text { double blind, } \\
\text { parall. }\end{array}$ & 40 & 20 & & 20 & Occlusal splints & GaAlAs $-820 \mathrm{~nm}, 300 \mathrm{~mW}, 3 \mathrm{~J} / \mathrm{cm}^{2}, 10 \mathrm{~s}$ & 10 & 30-90 days & 5 \\
\hline $\begin{array}{l}\text { Pereira et al, } \\
2014^{8}\end{array}$ & $\begin{array}{c}\text { Rand., pros., } \\
\text { double blind } \\
\text { parall. }\end{array}$ & 19 & $\begin{array}{l}19 \text { side } \\
\text { face }\end{array}$ & & $\begin{array}{l}19 \text { side } \\
\text { face }\end{array}$ & $\begin{array}{c}\text { GaAlAs - } 795 \mathrm{~nm} \\
100 \mathrm{~mW}, 8 \mathrm{~J} / \mathrm{cm}^{2} \\
\text { infra red, } 40 \mathrm{~s}\end{array}$ & $\begin{array}{c}\text { GaAlAs - } 660 \mathrm{~nm}, 100 \mathrm{~mW}, 4 \mathrm{~J} / \mathrm{cm}^{2} \text { in TMJ, } \\
\text { red } 40 \mathrm{~s}\end{array}$ & 3 & NA & 3 \\
\hline $\begin{array}{c}\text { Venezian et al, } \\
2010^{15}\end{array}$ & $\begin{array}{l}\text { Rand., pros., } \\
\text { double blind, } \\
\text { parall. }\end{array}$ & 48 & 24 & & 24 & $\begin{array}{l}\text { GaAlAs }-780 \mathrm{~nm}, \\
60 \mathrm{~mW}, 60 \mathrm{~J} / \mathrm{cm}^{2} \\
40 \mathrm{~s}\end{array}$ & GaAlAs - $780 \mathrm{~nm}, 50 \mathrm{~mW}, 25 \mathrm{~J} / \mathrm{cm}^{2}, 20 \mathrm{~s}$ & 8 & NA & 4 \\
\hline
\end{tabular}

Rand.: Randomized. Pros.: Prospective. NA: Not applicable

Source: by the authors 
Figure 2 shows the risk of bias of each selected study.

\begin{tabular}{|c|c|c|c|c|c|c|c|}
\hline & 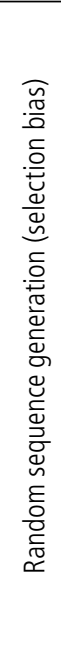 & 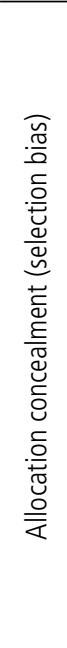 & 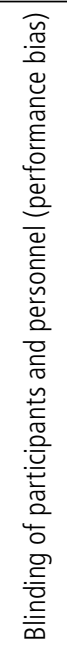 & 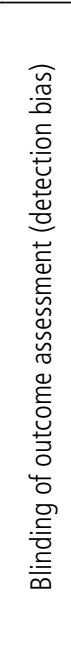 & 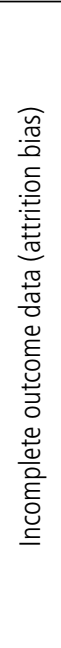 & 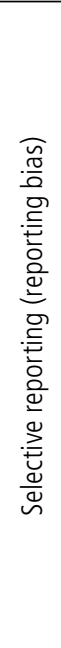 & $\begin{array}{l}\frac{\tilde{\sigma}}{0} \\
\frac{\bar{d}}{\dot{d}} \\
\frac{ \pm}{\Delta}\end{array}$ \\
\hline Cetiner et al, $2006^{2}$ & $?$ & + & + & $?$ & + & + & + \\
\hline Conti, $1997^{9}$ & $?$ & + & + & $?$ & + & + & + \\
\hline Cunha et al, $2008^{16}$ & $?$ & $?$ & + & $\theta$ & + & + & + \\
\hline Da Silva et al, $2012^{13}$ & $?$ & $?$ & + & + & + & + & + \\
\hline Dermikol et al, $2015^{17}$ & $?$ & $?$ & + & $?$ & + & + & + \\
\hline Emshoff et I, $2008^{5}$ & $?$ & + & + & + & + & + & + \\
\hline Fikackova et al, $2007^{7}$ & $?$ & $?$ & + & $?$ & + & + & + \\
\hline Kulekcioglu et al, $2003^{19}$ & $?$ & $?$ & + & $?$ & + & + & + \\
\hline Lima et al, $2013^{24}$ & $?$ & + & + & $?$ & + & + & + \\
\hline Mazzetto et al, $2010^{6}$ & $?$ & $?$ & + & + & + & + & + \\
\hline Melchior et al, $2013^{1}$ & $?$ & $?$ & O & 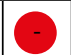 & + & + & + \\
\hline Öz et al, $2010^{14}$ & $?$ & + & + & + & + & + & + \\
\hline Pereira et al, $2014^{8}$ & $?$ & + & + & + & + & + & + \\
\hline Venezian et al, $2010^{15}$ & $?$ & + & + & + & + & + & + \\
\hline
\end{tabular}

Figure 2. Qualification of bias risk (RevMan version 5.3)

Source: by the authors

The main outcomes of each study are shown in Table 2 . 
Table 2. Summary of the main outcomes of the selected clinical trials

\begin{tabular}{|c|c|c|c|c|c|c|c|}
\hline \multirow[t]{2}{*}{ Author, year } & & \multicolumn{3}{|c|}{ Pain } & \multicolumn{3}{|c|}{ Mouth opening } \\
\hline & & Experimental & Control & Comparison & Experimental & Control & Comparison \\
\hline \multirow[t]{3}{*}{$\begin{array}{c}\text { Cetiner et al, } \\
2006^{2}\end{array}$} & Before & $7.56(+1.46)$ & $6.57(+1.91)$ & NA & $33.96 \pm 8.35$ & $35.83 \pm 8.66$ & NA \\
\hline & Immediately & $2.25(+2.05)$ & $5.60(+1.76)$ & NA & $39.67 \pm 6.45$ & $38.67 \pm 8.37$ & NA \\
\hline & 4 weeks & $0.82(+1.33)$ & $5.19(+2.01)$ & NA & $40.96 \pm 5.94$ & $38.58 \pm 8.42$ & NA \\
\hline \multirow[t]{2}{*}{ Conti, $1997^{9}$} & Before & 56 & 44 & NA & 0.561 & 0.024 & NA \\
\hline & 3 weeks & 20 & 46 & NA & 0.035 & 0.098 & NA \\
\hline \multirow[t]{2}{*}{$\begin{array}{l}\text { Cunha et al, } \\
2008^{16}\end{array}$} & Before & $6.87(+2.12)$ & & NA & & & \\
\hline & 4 weeks & $3.62(+2.45)$ & & NA & & & \\
\hline \multirow[t]{5}{*}{$\begin{array}{l}\text { Da Silva et al, } \\
2012^{13}\end{array}$} & Outset & & & & $32.0(+5.20)$ & $31.90(+4.40)$ & $32.30(+4.70)$ \\
\hline & Immediately & & & & $32.93(+5.51)$ & $32.27(+4.67)$ & $34.73(+5.35)$ \\
\hline & 5 applications & & & & $34.33(+4.94)$ & $31.87(+4.54)$ & $36.87(+4.30)$ \\
\hline & 10 applications & & & & $37.20(+4.81)$ & $31.53(+4.11)$ & $36.87(+4.22)$ \\
\hline & 5 weeks & & & & $35.80(+4.98)$ & $30.87(+4.11)$ & $34.80(+4.42)$ \\
\hline \multirow[t]{2}{*}{$\begin{array}{c}\text { Demirkol et al, } \\
2015^{17}\end{array}$} & Before & $6.45(+1.707)$ & $6.60(+1.506)$ & $7.40(+2.459)$ & & & \\
\hline & 3 weeks & $1.50(+2.273)$ & $2.0(+2.39)$ & $6.60(+2.319)$ & & & \\
\hline \multirow[t]{4}{*}{$\begin{array}{l}\text { Emshoff et al, } \\
2008^{5}\end{array}$} & Before & $38.2(+7.6)$ & $39.7(+12.2)$ & NA & & & \\
\hline & 2 weeks & $27.4(+17.5)$ & $25.2(+12.7)$ & NA & & & \\
\hline & 4 weeks & $20.9(+17.7)$ & $16.5(+15.0)$ & NA & & & \\
\hline & 8 weeks & $12.3(+16.1)$ & $11.8(+16.8)$ & NA & & & \\
\hline \multirow[t]{6}{*}{$\begin{array}{l}\text { Fikácková et al, } \\
2007^{7}\end{array}$} & Worsening acute pain & $0(0 \%)$ & $0(0 \%)$ & $0(0 \%)$ & & & \\
\hline & Worsening chronic pain & $1(4 \%)$ & $0(0 \%)$ & $1(6 \%)$ & & & \\
\hline & Unchanged acute pain & $1(11 \%)$ & $4(34 \%)$ & $3(30 \%)$ & & & \\
\hline & $\begin{array}{l}\text { Unchanged chronic } \\
\text { pain }\end{array}$ & $3(12 \%)$ & $8(100 \%)$ & $5(28 \%)$ & & & \\
\hline & Improved acute pain & $8(89 \%)$ & $7(66 \%)$ & $7(70 \%)$ & & & \\
\hline & Improved chronic pain & $20(84 \%)$ & $0(0 \%)$ & $12(67 \%)$ & & & \\
\hline \multirow[t]{3}{*}{$\begin{array}{l}\text { Kulekcioglu et al, } \\
2003^{19}\end{array}$} & Before & $42.88(+27.0)$ & $35.3(+29.0)$ & NA & $36.0(+8.0)$ & $37.4(+11.2)$ & NA \\
\hline & Immediately & $10.5(+8.4)$ & $8.0(+9.4)$ & NA & 42. $(+8.4)$ & $40.8(+8.9)$ & NA \\
\hline & 4 weeks & $5.5(+17.9)$ & $5.3(+6.4)$ & NA & $43.7(+7.4)$ & $40.8(+8.9)$ & NA \\
\hline $\begin{array}{l}\text { Lima et al, } \\
2013^{24}\end{array}$ & Without acute pain 1 & 0 & 34.4 & NA & 0 & 0 & NA \\
\hline
\end{tabular}




\begin{tabular}{|c|c|c|c|c|c|c|c|}
\hline \multirow[t]{2}{*}{ Author, year } & & \multicolumn{3}{|c|}{ Pain } & \multicolumn{3}{|c|}{ Mouth opening } \\
\hline & & Experimental & Control & Comparison & Experimental & Control & Comparison \\
\hline & Without chronic pain & 0 & 0 & NA & 19.2 & 19.2 & NA \\
\hline & Acute mild pain 1 & 0 & 65.6 & NA & 18.8 & 3.1 & NA \\
\hline & Chronic mild pain & 0 & 7.7 & NA & 53.8 & 30.8 & NA \\
\hline & Acute moderate pain 2 & 53.1 & 0 & NA & 81.3 & 46.9 & NA \\
\hline & Chronic moderate pain & 7.7 & 76.9 & NA & 26.9 & 34.5 & NA \\
\hline & Severe acute pain 2 & 43.8 & 0 & NA & 0 & 50 & NA \\
\hline & Severe chronic pain & 50 & 15.4 & NA & 0 & 15.4 & NA \\
\hline & Severe acute pain 2 & 3.1 & 0 & NA & & & NA \\
\hline & Severe chronic pain 3 & 42.3 & 0 & NA & & & NA \\
\hline \multirow[t]{4}{*}{$\begin{array}{l}\text { Mazzetto et al, } \\
2010^{6}\end{array}$} & Before & 5.40 & 5.80 & NA & 48.25 & 47.90 & NA \\
\hline & 8 applications & 2.10 & 4.45 & NA & 50.60 & 47.30 & NA \\
\hline & 7 days & 2.50 & 5.15 & NA & 50.25 & 47.5 & NA \\
\hline & 4 weeks & 2.95 & 5.60 & NA & 50.55 & 46.35 & NA \\
\hline \multirow[t]{2}{*}{ Öz et al, $2010^{14}$} & Before & 48.5 & NA & 52.7 & $44.20(6.14)$ & & $43.20(6.57)$ \\
\hline & 5 weeks & 16.8 & NA & 31.6 & $47.20(5.51)$ & & $44.45(5.90)$ \\
\hline \multirow[t]{5}{*}{$\begin{array}{l}\text { Pereira et al, } \\
2014^{8}\end{array}$} & Outset & $7.38(1.7)$ & NA & $6.91(1.6)$ & & & \\
\hline & 24 hours & $5.04(2.4)$ & NA & $4.65(2.5)$ & & & \\
\hline & 30 days & $4.76(2.8)$ & NA & $4.20(2.4)$ & & & \\
\hline & 90 days & $4.84(2.9)$ & NA & $4.44(2.5)$ & & & \\
\hline & 180 days & $4.95(2.9)$ & NA & $3.73(2.6)$ & & & \\
\hline \multirow[t]{6}{*}{$\begin{array}{l}\text { Venezian et al, } \\
\quad 2010^{15}\end{array}$} & Before & 7.66 & NA & 6.49 & & & \\
\hline & Immediately & 4.87 & NA & 3.45 & & & \\
\hline & 4 weeks & 5.37 & NA & 4.12 & & & \\
\hline & Before & 7.99 & NA & 7.37 & & & \\
\hline & Immediately & 4.8 & NA & 3.87 & & & \\
\hline & 4 weeks & 5.45 & NA & 3.87 & & & \\
\hline
\end{tabular}

The laser type most commonly used was GaAlAg. ${ }^{2,6,8,9,13-15}$ The wavelength ranged from $830 \mathrm{~nm}$ to $904 \mathrm{~nm}$, and the number of sessions ranged from 4 to 15 . The energy density used ranged from $1.5 \mathrm{~J} / \mathrm{cm}^{2}{ }^{5}$ to $52.5 \mathrm{~J} / \mathrm{cm}^{2}{ }^{13}$ 
An energy density of $3 \mathrm{~J} / \mathrm{cm}^{2}$ was used by some authors (Kulekcioglu $2003^{19}$, Fic ckov $2007^{7}$ and $\quad$ z 2010 14 ) in their clinical trials, with decreased pain in the groups treated by laser. Most authors used energy densities of $4 \mathrm{~J} / \mathrm{cm}^{2}$ and $8 \mathrm{~J} / \mathrm{cm}^{2}, 2,8,9,11,16,17$ with favorable results in terms of improvement in TMD symptoms.

Not all studies evaluated mouth opening. ${ }^{2,9,18}$ Cetiner $2006^{2}$ evaluated masticatory difficulty as the outcome and, using an adapted visual analog scale (VAS), found an improvement in the group that used LLLT.

Regarding the evaluation of pain in the muscle insertion points made by operator palpation, in some studies, groups treated with lasers showed an improvement in pain of up to 4 times the pain levels of the placebo

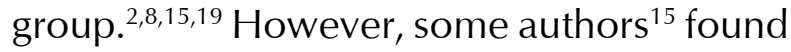
no significant difference between scores in this outcome after 4 weeks.

Kulekcioglu $2003^{19}$ evaluated pain as an outcome by counting the number of pain points in the musculature, finding out that pain reduction in the LLLT group was higher.

Some authors 2,6,9,13,19 evaluated jaw movements in terms of protrusion and laterality (in $\mathrm{mm}$ ), finding out an increase in dimensions of these jaw movements after LLLT.

\section{DISCUSSION}

In recent years, the use of lasers in dentistry has become a popular noninvasive treatment $^{2}$ with no side effects in terms of improvement of TMD symptoms, especially pain relief. As the treatment protocols available differ greatly from each other, professionals remain in doubt as to which the most effective is.
The pain produced by TMDs is intense and may interfere with a person's daily activities. It also causes difficulty in terms of jaw movements, decreasing chewing ability and quality of nutrition, ${ }^{20,21}$ and consequently patient's quality of life.

The clinical trials evaluated show that different types of laser have been proposed to reduce TMD symptoms. All show different effects on analgesia, some without significant differences from the placebo (Emshoff et al $2008^{5}$ and Demirkol et al 2015 ${ }^{17}$ ). Others (Cetiner 2006 ${ }^{2}$ and Mazzetto 20106) have used the same type of laser, showing significant analgesia 3 and 4 times higher than those of their control groups. However, these differences reveal a variety of outcomes, which are not comparable with each other because the doses used were different, demonstrating the difficulties in making comparisons by meta-analysis to find evidence of one treatment being superior to another in order to establish a standardized protocol.

The laser type most commonly used for analgesia was GaAlAg., ${ }^{2,6,7,11-13}$ Although different doses were involved, this finding suggests that the GaAlAg laser should be the principal type to be tested in future standardized randomized clinical trials, measuring its outcomes to obtain evidence.

This systematic review shows that different wavelength types have been used and that most researchers report favorable results in terms of TMD symptom remission when using average lengths of 646 and $947 \mathrm{~nm}$. It is known that the LLLT wavelength is related to the degree of penetration according to different clinical needs. ${ }^{22,23}$ It has been well established that infrared lasers with longer wavelengths have more penetrative power and have been the most used in clinical 
trials, with wavelengths of $830 \mathrm{~nm}, 904 \mathrm{~nm}$ and $1064 \mathrm{~nm} .{ }^{13,17,19}$ However, some authors (Emshoff $2008^{5}$ and Pereira 2014 ${ }^{8}$ ) have demonstrated the use of red lasers $(632 \mathrm{~nm}$ and $660 \mathrm{~nm}$ ) in the improvement of pain symptoms in their LLLT groups.

Regarding energy and density values, only two studies (Mazzetto et $\mathrm{al}^{6}$ and Venezian et al. $2010^{15}$ ) used the same power of $50 \mathrm{~mW}$. Others ${ }^{2,5,6,14,16}$ used different power settings ranging from $17 \mathrm{~mW}$ to $500 \mathrm{~mW}$. Thus, concerning this parameter, the data were too variable to compare. However, it is known that establishing these values is very important since there is a high possibility of causing microthermal damage at the cellular level. ${ }^{23}$

In addition to wavelength and energy, another very important aspect of LLLT is the number of sessions and the laser application time required to cause biochemical reactions to produce the analgesic and anti-inflammatory effects, which must be exact for each case according to pain intensity. There is also no agreement among authors in this regard. What we can conclude is that an average of nine sessions ${ }^{2,6,7,13,15,17}$ with monitoring every 4 to 5 weeks appears to produce results favorable to the reduction of TMD symptoms.

Temporomandibular dysfunctions reduce quality of life due to the presence of pain, limitations in mouth opening and difficulty in performing lateral movements and protrusion of the jaw. Not all researchers choose to evaluate the same parameters. ${ }^{13}$ We found out that most researchers partially evaluate pain as a TMD parameter, possibly due to its wide range and intensity. Pain is a subjective sensation, and we found great variability of measurement methods and results in the clinical trials studied. This outcome may be questionable from the point of view of precision when interpreting whether the laser therapy worked or not. Mouth opening and range of jaw movements might be more objective parameters to determine whether a therapy had a beneficial effect.

Regarding the evaluation of pain by palpation of soft points, the group treated by laser reported pain reduction, compared with the group that received placebo. There is no consensus regarding how to evaluate muscle pain points, which makes it difficult to establish replicable and viable protocols. Some clinical trials measured each muscle in isolation, ${ }^{6}$ while others conducted the evaluation by identifying pain points around the TMJ region. ${ }^{19}$ This variability in evaluation techniques also leads to a lack of standardization.

The difficulty in mouth opening is an important component of symptomology; however, not all studies considered this outcome. 5,14,16,17,19 Da Silva et al $2012^{13}$ and Lima et al $2013^{24}$ reported a significant improvement in mouth opening; however, other clinical trials also showed clinical improvement in the laser-treated group, but with lower statistical significance. 11,13,24 $^{2}$

The difficulty in chewing was not evaluated in most clinical trials. Only Cetiner et al $2006^{2}$ evaluated this factor as an outcome. Some authors $^{6,9,19}$ evaluated jaw movements in terms of protrusion and lateralization. These findings suggest that other clinical trials should be conducted to establish a protocol for treating TMD symptoms. Perhaps a clinical trial involving a larger number of objective parameters for diagnosis and comparing the outcomes of different therapies would be more powerful in terms of verifying the therapeutic effectiveness of laser treatment. 
Finally, this systematic review shows that there are no established LLLT protocols for decreasing TMD symptoms, whether in terms of wavelength, power, energy density, or number of sessions. Nevertheless, each study has shown in its own way that the therapy under evaluation is effective in terms of symptom remission.

\section{CONCLUSION}

LLLT may be considered an alternative in the relief of symptoms of clinical TMD manifestations; however, there is no evidence of one protocol being superior to all the others.

\section{CONFLICT OF INTEREST}

The authors declare that they have no conflict of interest.

\section{CORRESPONDING AUTHOR}

Kleber Vallejo Rosero
University of S o Paulo
593999029364
klebervallejo@usp.br
Alemania N33-50 y Eloy Alfaro
Quito, Ecuador

\section{REFERENCES}

1. Melchior MO, Venezian GC, Machado BC, Borges RF, Mazzetto MO. Does low intensity laser therapy reduce pain and change orofacial myofunctional conditions? Cranio. 2013; 31(2): 133-9. DOI: https://doi. org/10.1179/crn.2013.021

2. Cetiner $\mathrm{S}, \mathrm{Kahraman} \mathrm{SA}, \mathrm{Y}$ cetas $\mathrm{S}$. Evaluation of low-level laser therapy in the treatment of temporomandibular disorders. Photomed Laser Surg. 2006; 24(5): 637-41. DOI: https://doi.org/10.1089/ pho.2006.24.637

3. Acosta R, Roura N. Una revisi n de la literatura sobre la relaci $n$ causal entre los factores oclusales (FO) y los des rdenes temporomandibulares (DTM) II: estudios epidemiol gicos anal ticos de observaci n. Rev Fac Odontol Univ Antioq. 2009; 21(1): 98-111.

4. Fricton JR, Olsen T. Predictors of outcome for treatment of temporomandibular disorders. J of Oral Facial Pain. 1996; 10(1): 54-65.

5. Emshoff R, B sch R, P mpel E, Sch ning H, Strobl H. Low-level laser therapy for treatment of temporomandibular joint pain: a double-blind and placebo-controlled trial. Oral Surg Oral Med Oral Pathol Oral Radiol Endod. 2008; 105(4): 452-6. DOI: https://doi.org/10.1016/j.tripleo.2007.09.012

6. Mazzetto MO, Hotta TH, Pizzo RC. Measurements of jaw movements and TMJ pain intensity in patients treated with GaAIAs laser. Braz Dent J. 2010; 21(4): 356-60.

7. Fik ckov H, Dostalov T, Navr til L, Klaschka J. Effectiveness of low-levellaser therapy in temporomandibular joint disorders: a placebo-controlled study. Photomed Laser Surg. 2007; 25(4): 297-303.DOI: https://doi. org/10.1089/pho.2007.2053

8. Pereira TS, Flecha OD, Guimaraes RC, de Oliveira D, Botelho AM, Ramos Gloria JC et al. Efficacy of red and infrared lasers in treatment of temporomandibular disorders - a double-blind, randomized, parallel clinical trial. Cranio. 2014; 32(1): 51-6. DOI: https://doi.org/10.1179/0886963413Z.0000000005 
9. Conti PC. Low level laser therapy in the treatment of temporomandibular disorders (TMD): a double-blind pilot study. Cranio. 1997; 15(2): 144-9.

10. De Godoy $\mathrm{CH}$, Silva PF, de Araujo DS, Motta LJ, Biasotto-Gonzalez DA, Politti F et al. Evaluation of effect of low-level laser therapy on adolescents with temporomandibular disorder: study protocol for a randomized controlled trial. Trials. 2013; 14: 229. DOI: https://doi.org/10.1186/1745-6215-14-229

11. Salmos-Brito JA, de Menezes RF, Teixeira CE, Machado Gonzaga RK, Rodrigues BH, Braz R et al. Evaluation of low-level laser therapy in patients with acute and chronic temporomandibular disorders. Lasers Med Sci. 2013; 28(1): 57-64. DOI: https://doi.org/10.1007/s10103-012-1065-8

12. Moher D, Shamseer L, Clarke M, Ghersi D, Liberati A, Petticrew M et al. Preferred reporting items for systematic review and meta-analysis protocols (PRISMA-P) 2015 statement. Syst Rev. 2015; 4(1): 1. DOI: https://doi.org/10.1186/2046-4053-4-1

13. Da Silva MA, Botelho AL, Turim CV, da Silva AM. Low level laser therapy as an adjunctive technique in the management of temporomandibular disorders. Cranio. 2012; 30(4): 264-71. DOI: https://doi. org/10.1179/crn.2012.040

14. z S, G kcen-R hlig B, Saruhanoglu A, Tuncer EB. Management of myofascial pain: low-level laser therapy versus occlusal splints. J Craniofac Surg. 2010; 21(6): 1722-8. DOI: https://doi.org/10.1097/ SCS.0b013e3181f3c76c

15. Venezian GC, da Silva MA, Mazzetto RG, Mazzetto MO. Low level laser effects on pain to palpation and electromyographic activity in TMD patients: a double-blind, randomized, placebo-controlled study. Cranio. 2010; 28(2): 84-91. DOI: https://doi.org/10.1179/crn.2010.012

16. Da Cunha LA, Firoozmand LM, da Silva AP, Camargo SE, Oliveira W. Efficacy of low-level laser therapy in the treatment of temporomandibular disorder. Int Dent J. 2008; 58(4): 213-7.

17. Demirkol N, Sari F, Bulbul M, Demirkol M, Simsek I, Usumez A. Effectiveness of occlusal splints and low-level laser therapy on myofascial pain. Lasers Med Sci. 2015; 30(3): 1007-12. DOI: https://doi. org/10.1007/s10103-014-1522-7

18. Scalize PH, de Sousa LG, Regalo SCH, Semprini M, Pitol DL, da Silva GA et al. Low-level laser therapy improves bone formation: stereology findings for osteoporosis in rat model. Lasers Med Sci. 2015; 30(5): 1599-607. DOI: https://doi.org/10.1007/s10103-015-1773-y

19. Kulekcioglu S, Sivrioglu K, Ozcan O, Parlak M. Effectiveness of low-level laser therapy in temporomandibular disorder. Scand J Rheumatol. 2003; 32(2): 114-8.

20. Bertolucci LE, Grey T. Clinical analysis of mid-laser versus placebo treatment of arthralgic TMJ degenerative joints. Cranio. 1995; 13(1): 26-9.

21. Moreira Rodrigues da Silva MA, Botelho AL, Turim CV, Bettoni Rodrigues da Silva AM. Low level laser therapy as an adjunctive technique in the management of temporomandibular disorders. Cranio. 2012; 30(4): 264-71. DOI: https://doi.org/10.1179/crn.2012.040

22. Trullols Casas C, Espa a Tost AJ, Berini Ayt s L, Gay Escoda C. Aplicaciones dell ser blando en odontolog a. An Esp Odontoestomatol. 1997; 2: 45-51.

23. Oltra-Arimon D, Espa a-Tost AJ, Berini-Ayt s L, Gay-Escoda C. Aplicaciones del I ser de baja potencia en odontolog a. RCOE. 2004; 9(5): 517-24.

24. Salmos-Brito JAL, de Menezes RF, Teixeira CEC, Gonzaga RKM, Rodrigues BHM, Braz R et al. Evaluation of low-level laser therapy in patients with acute and chronic temporomandibular disorders. Lasers Med Sci. 2013; 28(1): 57-64. DOI: https://doi.org/10.1007/s10103-012-1065-8 